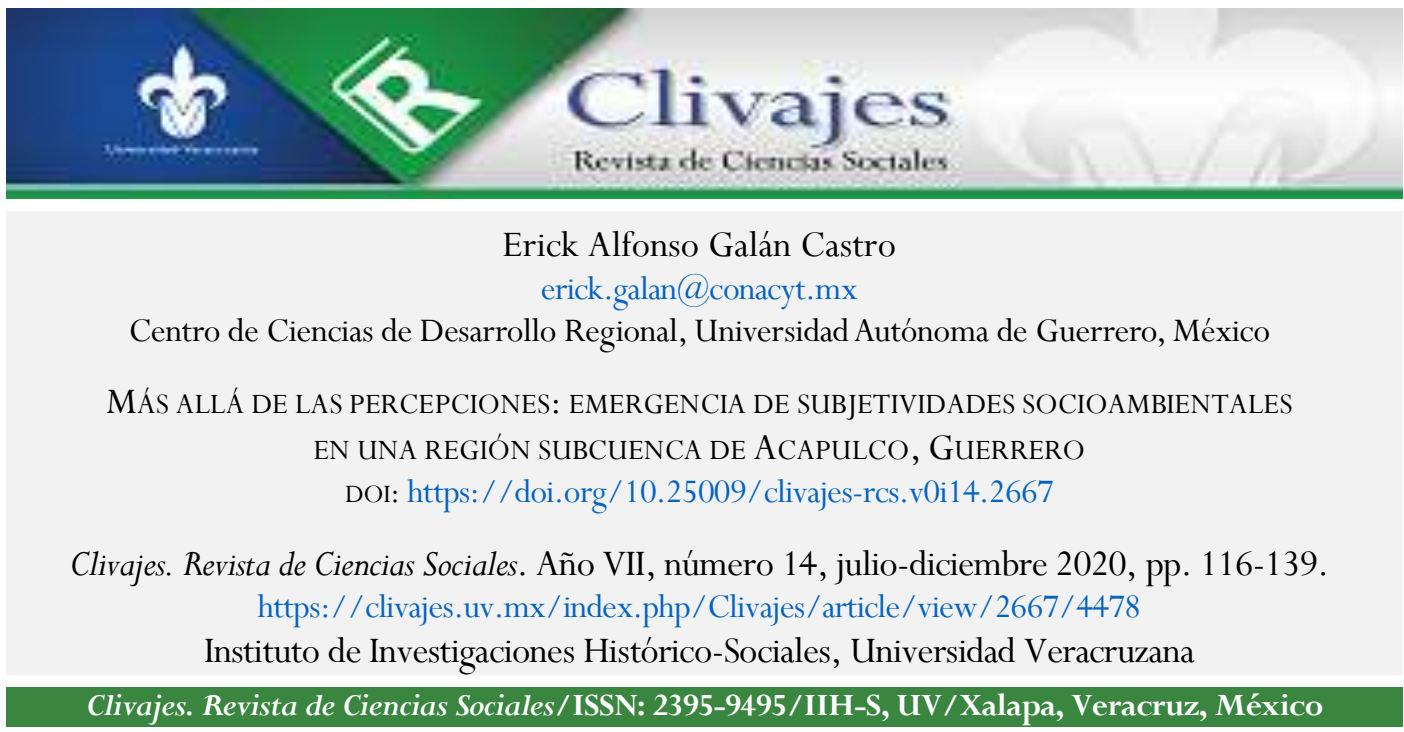

Recibido: 28/02/2020

Aceptado: 10/03/2020

Dictaminado: 16/11/2020 


\title{
MÁS ALLÁ DE LAS PERCEPCIONES: EMERGENCIA DE SUBJETIVIDADES SOCIOAMBIENTALES EN UNA REGIÓN SUBCUENCA DE ACAPULCO, GUERRERO
}

\author{
Erick Alfonso Galán Castro*
}

\section{Resumen}

El objetivo de este trabajo es analizar las subjetividades emergentes en la relación sociedad-naturaleza, en las comunidades y espacios urbanos de la subcuenca del río La Sabana-laguna de Tres Palos, la cual se caracteriza por el proceso de degradación del ecosistema ribereño, a causa de la disposición ilegal de residuos sólidos y la descarga de aguas negras, así como de la creciente violencia criminal en la zona. Parte del estudio de la gubernamentalidad, así como del análisis cualitativo de experiencias acerca del conflicto socioambiental, para proponer dos formas de construcción de sentido y de acción social: una biopolítica socioambiental (homo economicus), basada en la incidencia tecnificada sobre el problema, aunque carente de crítica hacia el modelo económico; y una necropolítica socioambiental (endriago), que responde al abandono estatal y genera acciones para la sobrevivencia, aunque fuera de la legalidad y contra la vida de otros.

Palabras clave: Gubernamentalidad, Conflicto socioambiental, Subjetividades emergentes

\section{BEYOND PERCEPTIONS. EMERGENCE OF SOCIO-ENVIRONMENTAL SUBJECTIVITIES IN A SUB-BASIN REGION OF ACAPULCO, GUERRERO}

\section{Summary}

The objective of this work is to analyze the emerging subjectivities in the society-nature relationship, in the communities and urban spaces of the sub-basin of the La Sabana-laguna de Tres Palos river, which is characterized by the degradation process of the riparian ecosystem, due to the illegal disposal of solid waste and the discharge of sewage, as well as the increasing criminal violence in the area. It is based on the study of governmentality, as well as the qualitative analysis of experiences about the socio-environmental conflict, to propose two forms of construction of meaning and social action: a socio-environmental bio-politics (homo economicus), based on the technological impact on the problem, although lacking criticism of the economic model; and a socioenvironmental necro-politics (endriago), which responds to state abandonment and generates actions for survival, although outside of legality and against the lives of others.

Keywords: Governmentality, Socio-environmental conflict, Emerging subjectivities

\section{AILLEURS DES PERCEPTIONS. ÉMERGENCE DE SUBJECTIVITÉS SOCIO ENVIRONNEMENTALES DANS UNE RÉGION SOUS BASSIN D’ACAPULCO, GUERRERO}

\section{Résumé}

L'objectif de ce travail est celui d'analyser les subjectivités émergeantes dans la relation société-nature, dans les communautés et espaces urbains du sous bassin de la rivière La Sabana-laguna de Tres Palos, qui se caractérise par le processus de dégradation de l'écosystème riverain, à cause de la disposition illégale de résidus solides et la décharge des eaux d'égout, ainsi que de la croissante violence criminelle de la zone. On part de l'étude de la gouvernabilité, ainsi que de l'analyse qualitative d'expériences à propos le conflit socio environnementale, pour proposer deux formes de construction de sens et d'action sociale : une biopolitique socio environnementale (homo economicus), basée dans l'incidence technicisée sur le problème, même dépourvu de critique envers le modèle

\footnotetext{
* Doctor en Investigación en Ciencias Sociales (FLACSO). Catedrático CONACYT, comisionado al Centro de Ciencias de Desarrollo Regional de la Universidad Autónoma de Guerrero, México. Contacto: erick.galan@conacyt.mx. 
économique ; et une nécro politique socio environnementale (endriago), qui répond à l'abandon de l'état et génère des actions pour la survivance, même hors de la légalité et contre la vie des autres.

Mots clés : Gouvernabilité, Conflit socio environnemental, Subjectivités emergentes

\section{INTRODUCCIÓN}

Acapulco es una ciudad que, desde mediados del siglo pasado, ha crecido de manera sostenida debido principalmente a toda una serie de proyectos gubernamentales para hacer del otrora puerto de desembarco del Galeón de Manila (llamado también La Nao de China) un destino turístico de proyección internacional. Desde la construcción, en 1927, de la carretera federal México-Acapulco, hasta la construcción de la Autopista del Sol, en 1993, el acceso principal al puerto, desde el centro del país, se hallaba en un camino que bordeaba la orilla del río La Sabana, uno de los dos cauces fluviales más importantes de la ciudad, junto con el río Papagayo, que abastece de agua potable a gran parte de la zona urbana. ${ }^{1}$

Con la construcción de dicha carretera, fueron surgiendo diversas comunidades a la vera del río, aunque ya había asentamientos con una historia relativamente larga, como La Providencia, donde se encontraba una hacienda antaño propiedad del general Juan Álvarez, o Paso Texca, en la que, en 1830, se libró una batalla crucial entre las fuerzas leales al entonces presidente Vicente Guerrero y los militares que posteriormente lo depusieron (liderados por José Gabriel de Armijo, muerto en acción en esta batalla) (Bartra, 1996; Illades, 2000); sin embargo, la construcción de la carretera federal trajo nuevos habitantes que constituyeron comunidades carentes de nombres propios tomados de la historia o de las costumbres locales: se llamaron "Kilómetro 40", “Kilómetro 32", "Kilómetro 30”, etc. Asimismo, como producto de la demanda de espacios habitacionales para la población que llegó de todas partes del estado de Guerrero a trabajar en la creciente industria turística, en los años 80 se construyó Ciudad Renacimiento, un complejo habitacional, cercano al río de La Sabana, que con el paso del tiempo no sólo dio origen a una gran cantidad de residuos sólidos y de aguas residuales tiradas al cauce de La Sabana, sino también a uno de los espacios de mayor inseguridad en Acapulco (Illades \& Santiago, 2019).

En anteriores acercamientos, Galán, Rodríguez y Rosas (2020) han encontrado más que problemas de carácter ambiental en la subcuenca, como el desbordamiento del río en temporada de lluvias; sequías, escasez de agua potable y un acelerado ritmo de cambio de uso de suelo en áreas antes cultivables, ahora convertidas en terrenos habitacionales. El vínculo entre el agotamiento de los recursos naturales, la baja calidad del agua del río -usado

${ }^{1}$ Agradecemos la colaboración del maestro Raúl Torres Rico y del ingeniero Ramiro Salvador Gómez Villerías, estudiantes de Doctorado en Ciencias Ambientales. 
desde hace más de 30 años como zona de confinamiento de aguas residuales-, el aumento de la violencia criminal, además del incremento de actividades como el comercio no formal y el mercadeo de recursos hídricos, por parte de grupos delincuenciales, se ha hecho cada vez más evidente en un esquema de relaciones entre actores ciudadanos y estatales, basado en un conjunto de dispositivos generados desde la gubernamentalidad, para gestionar la escasez de recursos naturales en contextos de violencia y criminalidad, denominado seguridad socioambiental.

Aunque, en principio, este esquema que da pie a la puesta en marcha de mecanismos legales e ilegales, para gestionar los recursos naturales y proveer de un sentimiento de suficiencia estatal frente a la escasez, es también el escenario para la implementación de mecanismos autoritarios de gobierno - que pueden ser controlados por los mismos actores gubernamentales- y para el surgimiento de amenazas por la disputa de territorios y recursos naturales, la pregunta a responder aquí es ¿cómo se construye sentido, cómo se sobrevive en un escenario violento, impactado ambientalmente y permeado por la ilegalidad y la lucha por el control de los recursos hídricos?

El objetivo de este trabajo es analizar las subjetividades emergentes en la relación sociedad-naturaleza en las comunidades y espacios urbanos que constituyen la subcuenca del río La Sabana-laguna de Tres Palos, que se caracteriza por el proceso degradativo del ecosistema ribereño, causado por la disposición ilegal de residuos sólidos y la descarga de aguas negras, así como por la creciente violencia criminal en la zona. Partimos de la analítica de la gubernamentalidad (Foucault, 2000; 2007; 2018; Mbembé, 2006; Estévez, 2019; Valencia, 2010) y de un análisis cualitativo de experiencias del conflicto socioambiental, para proponer dos formas de construcción de sentido y de acción social: una biopolítica socioambiental (homo economicus), basada en una incidencia tecnificada sobre el problema, aunque carente de crítica hacia el modelo económico (Estévez, 2019); y una necropolítica socioambiental (endriago), que responde al abandono estatal, generando acciones para la sobrevivencia, aunque éstas puedan darse fuera de la legalidad y contra la vida de otros (Valencia, 2010).

$\mathrm{Al}$ respecto, es importante mencionar trabajos previamente desarrollados, dentro y fuera de la zona de estudio, en los que se ha recogido la perspectiva de los actores sobre las problemáticas socioambientales. Un primer grupo de autores -principalmente los que estudian la zona- parte de la categoría de percepciones ambientales para analizar la forma en que los habitantes de las comunidades del río La Sabana y la laguna de Tres Palos hacen sus propias valoraciones y evaluaciones del impacto ambiental, sin necesariamente tener conocimientos sistemáticos y científicos sobre problemas relacionados con la huella humana en el medio ambiente; como resultado, este grupo de autores tiende a desvalorizar, incluso a 
criminalizar la forma en que los actores significan su relación con el medio ambiente (López et al., 2013; De la Llata, Juárez \& Sampedro, 2018; Del Carmen et al., 2018). Otros autores se basen en el análisis de dichas construcciones de sentido; hacen otro acercamiento desde el punto de vista de los saberes ambientales, partiendo de la idea de que los conocimientos, cosmovisiones, relatos fundacionales y procedimientos de uso de recursos naturales tienen un sentido más profundo y ambientalmente sostenible, que las imposiciones legales y políticas del Estado y otros grupos económico-políticos (Rosas \& Cortés, 2018; Rodríguez, 2017; Sánchez Infante \& Rosas, 2018).

En otras latitudes, el concepto de subjetividades socioambientales ha sido utilizado de manera recurrente para integrar tanto el análisis de la construcción del sentido simbólico que subyace a la relación entre los seres humanos y el entorno ambiental, como el análisis de los conflictos sociales y políticos desde los que dichas construcciones simbólicas adquieren presencia histórica (De la Garza, 2000). De acuerdo con Enrique de la Garza, quien cita a Bourdieu, Habermas y Foucault como referencias teóricas, la subjetividad es un proceso de producción de significados individual y a la vez colectivo, que no se generan únicamente desde el espacio de las interacciones, sino también considerando las limitantes espaciales, temporales y por las condicionantes culturales (los significados acumulados socialmente que los actores no escogen). Del mismo modo, resalta el carácter impositivo que puede llegar a tener frente a otros actores en un marco de relaciones de poder como otra limitante, ésta de carácter estructural (De la Garza, 2000, p. 3).

Vemos, de esta manera, estudios que abordan la construcción de subjetividades socioambientales en choque con la implementación de proyectos económicos extractivistas, que mezclan la crítica al capitalismo con la defensa de las comunidades étnicas o campesinas (Del Cairo, Montenegro-Perini \& Vélez, 2014; Navarro \& Pineda, 2009; Trentini \& Sorroche, 2016); otros estudios se concentran en la utilización de elementos significativos como el uso del cuerpo, la identidad comunitaria y las emociones (Navarro, 2013), y la utilización de construcciones discursivas referentes a la memoria colectiva o la emergencia de propuestas a futuro - proyecto-, como elemento subjetivador (Tischler \& Navarro, 2011).

Si bien la categoría de subjetividades socioambientales no es nueva y ha tenido un abordaje abundantemente documentado en México y Latinoamérica, el caso de los actores que habitan la subcuenca del río La Sabana y la laguna de Tres Palos puede ser analizado bajo esta óptica, en la medida en que la evidencia empírica ha permitido observar que las disputas entre los actores por el aprovechamiento de los recursos naturales y la habitabilidad del territorio supone una coexistencia entre construcciones discursivas que buscan legitimar posiciones políticas en torno al territorio, y acciones que finalmente repercuten tanto en la 
gestión de los recursos como en la emergencia de otras problemáticas; por ejemplo, la pobreza, la persistencia de cacicazgos, la emergencia de grupos criminales organizados, y, en términos generales, la disputa por la mera sobrevivencia y las condiciones para generar vida.

Este estudio parte de una perspectiva analítica que se ha venido construyendo con el fin de entender el vínculo entre la constante degradación ambiental de los recursos naturales en el área de estudio y su alta conflictividad social y económica. El concepto de seguridad socioambiental ha sido útil para comprender la relación entre habitantes de la subcuenca, actores gubernamentales, actores de la sociedad civil y grupos que operan por fuera de la legalidad estatal y buscan incidir sobre dicha problemática territorial. La seguridad socioambiental consiste en el conjunto de dispositivos generados desde la gubernamentalidad para gestionar la escasez de recursos naturales en contextos de violencia y criminalidad, suponiendo así dos vías posibles de gestión: una orientada a garantizar, al mismo tiempo, el control de daños y la gestión sustentable de recursos naturales - una biopolítica socioambientaly otra que supondría no sólo el manejo extensivo y no circular de recursos naturales, sino el abandono y la eliminación manifiesta de poblaciones en el marco de luchas por la sobrevivencia - una necropolítica socioambiental-.

Foucault define la biopolítica como una orientación de la razón de Estado, diferente a la del poder ejercido desde el feudalismo, que se caracterizaba por el dominio negativo de los cuerpos para dar muerte a los enemigos; en este caso, la razón de Estado orientada hacia la biopolítica supone el uso del poder mediante el control, la preservación del cuerpo, su uso productivo en la dinámica económica: dejar vivir (Foucault, 2007, p. 44, y 2018, pp. 164165). La biopolítica se hace presente en la relación sociedad-naturaleza, a partir de la elaboración de políticas o actos de gobierno que generen control sobre los sujetos con base en la propia idea de la defensa del bios; ejemplo de ello es la noción dominante de sustentabilidad, que, si bien para Enrique Leff (2000) es un proyecto de sociedad tendiente a la reflexión crítica de la economización del mundo y los efectos nocivos que esta última ha generado en aras de la justicia social y ambiental (p. 61), lo cierto es que, en su forma de desarrollo sustentable, ha sido una estrategia política de homogenización de la producción económica capitalista, la cual limita las experiencias de autogestión comunitaria, bajo un discurso ambiental, en aras de una mayor acumulación de capital; en suma, el desarrollo sostenible se vuelve una estrategia más para sostener el desarrollo (Esteva, 1997, p. 28).

Por otro lado, Achille Mbembé (2006) formuló el concepto de necropolítica para definir los mecanismos de gobierno de los Estados africanos que pasaban por un proceso de inestabilidad interna y debilidad institucional que se reflejaba en el genocidio. Para Mbembé, el proceso de modernidad en África no derivó en un mayor refinamiento de los mecanismos de control aplicados desde el Estado, como afirma Foucault, sino en la eliminación de los 
gobernados como política deliberadamente planeada y sustentada normativamente. A ese dejar morir, al uso de las capacidades estatales para abandonar, rechazar, o eliminar de manera consciente a las poblaciones, es precisamente a lo que Mbembé denomina necropolítica (p. 19).

En este contexto de relaciones, proponemos que la emergencia de subjetividades socioambientales es una forma en la cual todos los actores involucrados buscan sobrevivir, sacar provecho, disputar o, en términos generales, incidir sobre la situación de escasez socioambiental.

METODOLOGíA

Figura 1

Subcuenca del río La Sabana y la laguna de Tres Palos en Acapulco, Guerrero

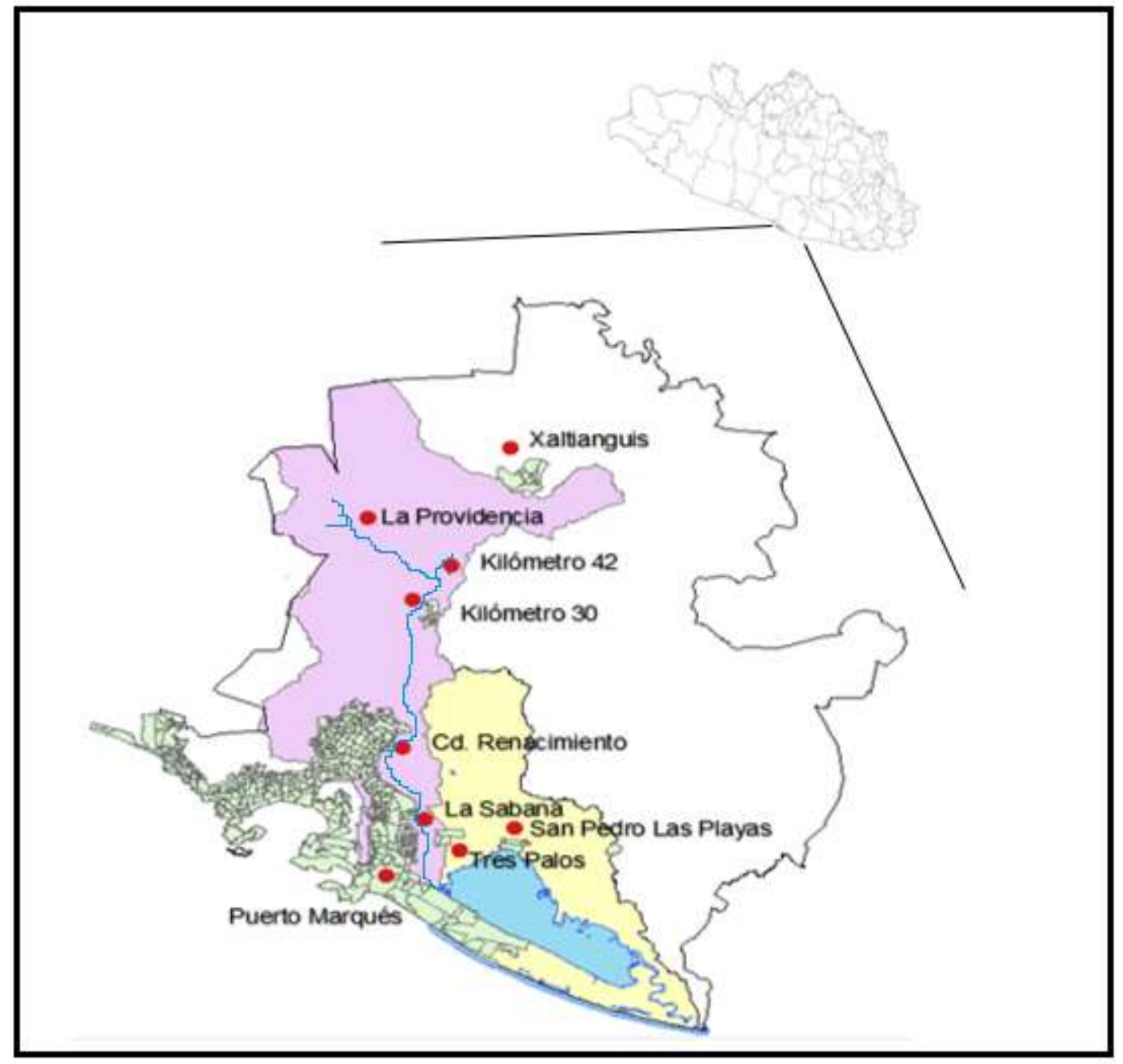

Fuente: Elaboración del Mtro. Raúl Torres Rico. 
La subcuenca del río La Sabana-laguna de Tres Palos agrupa 60 poblaciones, localizadas entre la comunidad La Providencia y la zona metropolitana de la ciudad de Acapulco, Guerrero (González, Quiterio, Niño, Reyes \& Torres, 2012, p. 14). El río La Sabana mide aproximadamente $57 \mathrm{~km}$, hasta llegar a la laguna de Tres Palos, que tiene una longitud máxima de 16 km y una anchura mayor a 6 km (Sánchez Infante \& Rosas, 2018, p. 195). El aumento de la población en las colonias que se asentaron cerca de la subcuenca en los últimos 20 años ha generado no sólo una mala calidad del recurso hídrico, sino también otros problemas de carácter social, económico y ambiental, como asentamientos irregulares que descargan aguas residuales de uso doméstico en el río La Sabana, manejo irregular de los residuos sólidos urbanos, degradación del suelo, pérdida masiva de cubierta vegetal, erosión, merma de recursos pesqueros y daños considerables en la zona turística de la laguna de Tres Palos (González et al, 2012, p. 24; Saldaña \& Pérez, 2015, p. 2; Sánchez Infante, 2018, p. 18).

La investigación a la cual remite este trabajo se desarrolló con base en la recolección y análisis de información cualitativa, especialmente a partir de dos formas de procesamiento de datos: elaboración de mapas mentales con códigos emergentes, y análisis de entrevistas como lectura teórica. Este análisis de entrevistas supone, como menciona Steinar Kvale (2011), 1) la lectura constante de las entrevistas previamente transcritas, 2) reflexiones teóricas sobre temas específicos de interés, y 3) ampliación de la teoría, a partir del diálogo con los actores dentro del texto científico (p. 151). Los hallazgos de investigación pueden presentarse en un texto interpretativo continuo, con pasajes de las diversas entrevistas intercalados, a modo de diálogo socrático o una confrontación (p. 152). Epistemológicamente, este tipo de análisis tiene sustento en la perspectiva falsacionista de la ciencia, desde la cual los enunciados teóricos no deben ser necesariamente tomados como reflejo idéntico de la realidad, sino que pueden ser confrontados, refutados o, incluso, ampliados (Popper, 1962).

Así pues, primero construimos un mapa de actores, en el cual consideramos las experiencias subjetivas de actores de la sociedad civil ambientalista de Acapulco (miembros de organizaciones civiles que han tenido incidencia en la construcción de la agenda ambiental municipal y estatal para la región subcuenca), actores gubernamentales de los tres niveles de gobierno y actores locales (habitantes con alguna participación en consejos comunitarios de gestión de agua, líderes locales y/o personas involucradas en la organización comunitaria de las localidades cercanas a la subcuenca). Preparamos un guion de entrevistas en las cuales se hizo hincapié en la relación entre seguridad socioambiental y subjetividades socioambientales, y llevamos a cabo 25 entrevistas a profundidad. Los criterios de selección de informantes fueron los siguientes: 1) la recomendación de colegas académicos del Centro 
de Ciencias de Desarrollo Regional de la Universidad Autónoma de Guerrero; 2) la recomendación de estos primeros informantes en relación con otros actores que ellos han identificado como importantes por su trayectoria (liderazgo local, trayectoria en puestos de gestión gubernamental, participación en el activismo ambientalista en Acapulco). Si bien, en un principio consideramos la puesta en marcha de acercamientos de corte etnográfico, diversos hechos de violencia y enfrentamientos intercomunitarios limitaron nuestro acercamiento a la región por este medio, lo que, por otra parte garantizó la integridad física de quienes participaron en la recolección de la información.

Ahora bien, por el tipo de análisis, basado en la lectura teórica de las entrevistas a profundidad, este trabajo de exposición de resultados no necesariamente muestra la totalidad de las entrevistas recabadas, sino aquellos extractos que permiten entablar el diálogo teórico entre el investigador, las categorías conceptuales que éste utilizó y la perspectiva de los actores; al final, sin embargo, se presentará una lista de los actores entrevistados. La elaboración del mapa semántico expuesto en la Figura 3 deriva de un ejercicio interpretativo posterior a la lectura y codificación de todo el material empírico. Por cuestiones de ética en la investigación, omitimos los nombres reales de los actores entrevistados, a los cuales asignamos un nombre ficticio para fines de diferenciación.

Figura 2. Mapa de actores para la elaboración de entrevistas a profundidad

\begin{tabular}{|c|l|}
\hline Tipo de actor & \multicolumn{1}{|c|}{ Afiliaciones o características } \\
\hline Sociedad Civil & $\begin{array}{l}\text { Integrantes de organizaciones no gubernamentales con agenda de protección al } \\
\text { ambiente, académicas(os). }\end{array}$ \\
\hline $\begin{array}{c}\text { Actores } \\
\text { gubernamentales }\end{array}$ & $\begin{array}{l}\text { Funcionarias(os) o exfuncionarias(os) municipales, estatales y federales. } \\
\text { Empleadas(os) con atención directa a la ciudadanía, personal técnico encargado de } \\
\text { manejo de agua, limpia pública, tratamiento de aguas residuales. }\end{array}$ \\
\hline $\begin{array}{c}\text { Actores Locales } \\
\text { Habitantes con o sin cargos de representación local de comunidades o colonias dentro } \\
\text { de zonas rurales o urbanas de la subcuenca. }\end{array}$ \\
\hline
\end{tabular}

Fuente: Elaboración propia.

\section{LAS SUBJETIVIDADES SOCIOAMBIENTALES COMO MECANISMOS DE GUBERNAMENTALIDAD}

Siguiendo la línea de discusión de Valencia (2010) y Estévez (2019), si bien para Foucault el proceso de subjetivación de actores no fue un elemento central de discusión, sus trabajos fueron el punto de partida para plantear preguntas en la investigación social: ¿Cómo se crea 
el sujeto en un entorno de control y desequilibrios de poder? ¿Cómo se objetiva el poder para salir del laberinto del control y el disciplinamiento? (Estévez, 2019, p. IX).

El contexto de la seguridad socioambiental supone que las acciones de gobierno, en el sentido foucaultiano - es decir, de control del disenso entre la población mediante dispositivos de seguridad (Foucault, 2018, p. 136)-, han sido constituidas históricamente para controlar poblaciones en disenso, por dos vías: 1) dando la apariencia de que atiende las causas del problema, a través de la provisión de espacios de cogestión ciudadana, indicadores para la medición de dicho problema a partir de discursividades construidas por medio de la razón de Estado - es decir, mecanismos racionalizados y moralmente aceptados, en un corte histórico (episteme) de la acción política, que caracterizan a la biopolítica (Foucault, 2007, p. 19)-; y 2) acotando el ámbito de acción del Estado, lo que da pauta a la participación de actores no legales - comunidades en desafío al Estado, grupos delincuenciales, prácticas de ilegalidad generadas cotidianamente por estos actores- y la emergencia de un control no necesariamente provisto por el Estado, pero funcional a los intereses de quienes detentan su poder institucional. ${ }^{2}$ La seguridad socioambiental es un conjunto de relaciones entre actores, que históricamente se enmarca en un momento de crisis del régimen neoliberal, y se caracteriza por producir escasez mediante la mercantilización de la vida: sólo tienen derecho a ésta los que pueden pagar por ella, y eso supone la generación de deuda (Lazzarato, 2013).

De acuerdo con nuestros resultados, hay dos formas emergentes de subjetividad socioambiental que coexisten en el contexto de la subcuenca del río La Sabana-laguna de Tres Palos: una subjetividad biopolítica, que en términos de Estévez (2019) podría denominarse homo economicus, y otra de carácter necropolítico, que Valencia (2010) llama endriago. A continuación se define cada una de estas categorías emergentes.

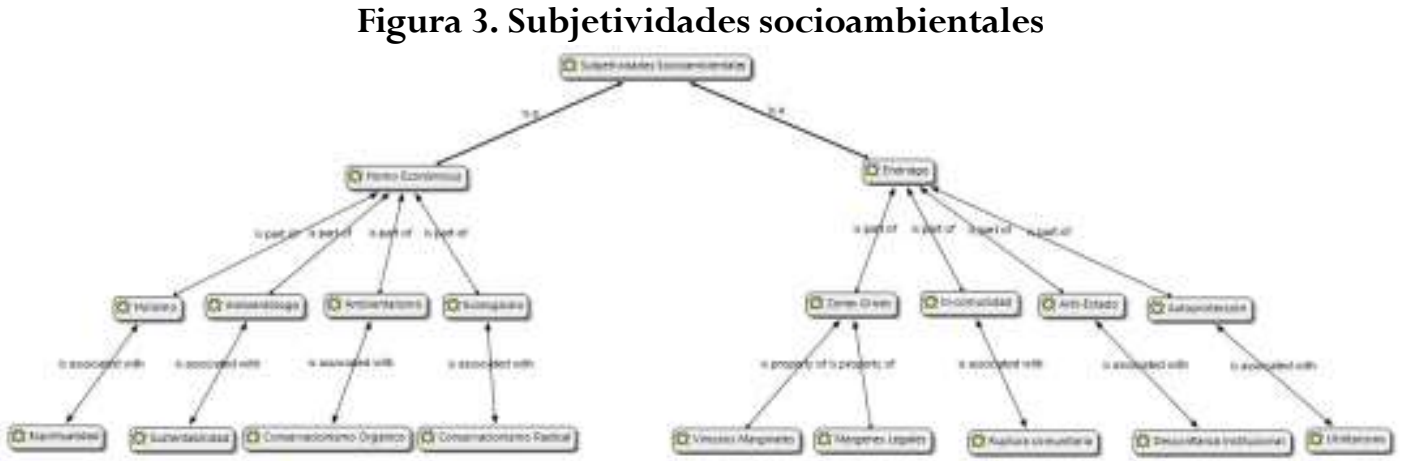

Fuente: Elaboración propia.

${ }^{2}$ Mbembé (2011) llama gobierno privado indirecto al sistema de relaciones políticas emergente en un contexto de desabasto, desinstitucionalización y desterritorialización; se caracteriza por el control político de las poblaciones a partir de actores que están fuera de la esfera estatal y operan al margen de ella, pero asumen papeles que, desde la lógica de la modernidad, han sido tradicionalmente atribuidos al Estado, como el cobro de impuestos, la distribución de bienes, la garantía de seguridad pública, etc. (pp. 79-80). 


\section{El homo economicus socioambiental}

Estévez (2019) habla del homo economicus como un empresario de sí mismo, y él mismo es su capital, productor, fuente de ganancias y generador de su propia satisfacción (p. XI); como tal, su fin último es mantener las condiciones necesarias para que esta autosatisfacción y autoproducción se mantengan constantes, lo cual no puede suceder si no se garantiza la vida misma. Si bien Foucault define al sujeto del biopoder como homo economicus que maximiza sus beneficios y minimiza los costos en toda relación social, llevando esta lógica a una constante búsqueda por la vida, prácticamente a toda costa (Foucault, 2007, pp. 264-266), el homo economicus socioambiental parte de la narrativa de la protección al ambiente y la construcción de seguridad, como formas de preservación de la vida en un entorno hostil. Este homo economicus parte de toda una serie de constructos discursivos como la sustentabilidad, el desarrollo, la amigabilidad con el medio ambiente, la conservación de los recursos naturales, etc., y los utiliza de tal modo que orienta su acción política al sostenimiento del modelo económico que ha dado forma a la noción de un Acapulco turístico con playas limpias, bellezas naturales y seguridad física para los turistas. De acuerdo con la información analizada, desde el punto de vista de los actores es posible construir al menos cuatro subcategorías del homo economicus ambiental: el ambientalista, el ambientólogo, el ecologista y el sujeto ambiental holístico.

El ambientalista se define como un actor político que orienta el sentido de su incidencia pública a proteger el medio ambiente sin sacrificar el modelo de desarrollo económico acapulqueño orientado al turismo. ${ }^{3}$ Construye una narrativa teleológica en la que el futuro se proyecta relativamente en el pasado, a partir de la recuperación de los tiempos del Acapulco limpio, atractivo para el turismo internacional por su tranquilidad provinciana y la abundancia de sus recursos naturales, pero sin sacrificar el crecimiento de su industria turística, directamente asociada con el desarrollo urbano y social de la ciudad. En ese sentido, el ambientalista se vuelve un sujeto orgánico al modelo económico-político centrado en el turismo, intercalando la racionalización de la relación vida-muerte con la emotividad

\footnotetext{
${ }^{3}$ Miriam Alfie (2001) habla acerca de la emergencia de tres tipos de nuevos movimientos sociales ambientalistas: los de tipo consciente y autorreflexivo, los de corte autoritario que defienden la tradición frente a los avances tecnológicos, y los de carácter híbrido que utilizan los medios globales para difundir su lucha, pero en el marco de contextos locales de alta exclusión y deterioro socioambiental (pp. 69-70).La emergencia de los grupos civiles ambientalistas en Acapulco, para el caso, retoma algunas de las cuestiones consideradas por Alfie, pero se presentan otras más. Si bien los actores civiles ambientalistas van surgiendo en el marco de una historia de autoritarismo subnacional y la coacción de gobiernos estatales y municipales para evitar mostrar una imagen "sucia" de Acapulco, grupos como Guerreros Verdes, Prodefensa de la Conservación de la Isla de la Roqueta, Colegio de Ecólogos de Acapulco, entre otros, han evidenciado las fuentes de la contaminación en aguas marinas y ribereñas desde principios de los años 90, pero también lo han hecho resaltando una identidad que relaciona al acapulqueño con la actividad turística. En ese sentido, se trata de un ambientalismo que no cuestiona el modelo económico extractivo - la industria turística-, sino que parte de ella como un criterio de construcción de identidades.
} 
de un pasado perdido que debe volver. Uno de los informantes, expresidente del Consejo de Cuenca del Río La Sabana-Laguna de Tres Palos, construye así la idea del ambientalista en oposición al ecologista.

(...) yo ya no pertenezco a Guerreros Verdes, lo dejé precisamente por diferencias con la directora. ¿Por qué?, porque yo considero que una cosa es el ambientalismo y otra cosa es el ecologista. Entonces, ella era una ecologista que no permitía nada más allá del desarrollo, y yo no puedo estar en contra del desarrollo de mi ciudad, tanto el desarrollo ambiental como el desarrollo económico.

(...) protegiendo el ambiente, pero con ciertas medidas de mitigación para revertir el daño que yo pueda causar; yo no puedo detener el desarrollo de mi ciudad, no puedo detener el que los ciudadanos tengan una mejor calidad de vida. (Julián, actor civil, comunicación personal).

El ambientólogo es el sujeto constructor de la razón de Estado, que mide los parámetros de equilibrio entre la vida y la muerte. Tiene una preparación académica sólida y pone sus esfuerzos técnicos y científicos en la elaboración de mecanismos que permiten a los actores gubernamentales definir los territorios y las poblaciones que pueden ser atendidos con medios estatales. Parten de una premisa muy extendida entre los analistas de política pública, desde la cual lo que no se mide, no se puede mejorar (Ernesto, actor gubernamental, comunicación personal). El sentido de su discurso está orientado por dos paradigmas de pensamiento no lejanos entre sí: la sustentabilidad y la seguridad pública. La sustentabilidad permitirá el aprovechamiento de los recursos naturales y de las capacidades técnicas estatales, sin que ambos se agoten ("Saber administrar los recursos", de acuerdo con Soledad, directora de una preparatoria en una comunidad rural de la subcuenca), y la seguridad pública garantizará que las poblaciones atendidas no se sientan amenazadas por la presencia de grupos criminales (la implementación de programas como Guerrero Seguro, en 2011, o de Polígonos Geográficos Prioritarios para atender las condiciones de inseguridad en Acapulco). ${ }^{4}$

Otro informante, exdirector del organismo operador de agua y saneamiento local (CAPAMA), habla de la importancia de estos parámetros de razón de Estado para dirimir conflictos políticos por los recursos hídricos.

\footnotetext{
${ }^{4}$ Guerrero Seguro fue un operativo de seguridad implementado a petición del entonces gobernador Ángel Aguirre Rivero, cuya finalidad fue sanear las corporaciones policiacas locales y tomar el control de la seguridad pública por parte de fuerzas federales en todo el estado de Guerrero (Illades \& Santiago, 2019). Luego de ello, durante el sexenio 2012-2018 y en el marco del Programa Nacional de Prevención Social de la Violencia y la Delincuencia, en el municipio de Acapulco se definieron cinco polígonos de atención prioritaria (de 57 propuestos para todo el país en función de los índices de criminalidad, y en donde se implementaron programas de apoyo social, psicológico y de desarrollo comunitario (Triana, 2017).
} 
(...) se han hecho esfuerzos desde hace muchos años, esfuerzos gubernamentales, de los tres niveles de gobierno, en este... desde hacer estudios de calidad del agua, porque lo que no se mide no se puede mejorar. Es decir, medir en qué condiciones de calidad del agua está un cuerpo receptor, pero monitorearlo de manera continua y permanente para ir viendo, ir viendo la degradación que pueda tener el cuerpo receptor, modificaciones, ¿sí? Y luego también tener indicadores...

(...) coincidimos con varias gentes que el dotar de infraestructura de agua potable, de drenaje, y drenaje, le corresponde al ayuntamiento. El ayuntamiento es la responsable de dotar de servicios públicos, ella es la responsable. Si una colonia se establece, solicita agua... y CAPAMA tiene que dar la factibilidad. El ayuntamiento le dice a CAPAMA: "Oye, ¿hay factibilidad?... Espérate, hay que hacer estudios, a ver si hay agua disponible. ¿Qué caso tiene que tú construyas infraestructura y no le llegue el agua? Después se vuelve un doble problema”. Entonces, si hay la factibilidad, el municipio tiene que construir la infraestructura, pero con proyectos de CAPAMA, autorizados por el organismo, pues (Ernesto, actor gubernamental, comunicación personal)

El ecologista es una suerte de conservacionista radical; parte de la constante crisis de los recursos comunes y de la crisis moral que supone el uso extensivo de éstos, y con base en esta problemática puede llegar a interpelar a los actores gubernamentales, aunque tampoco logra constituir una narrativa de resistencia. Sin ser propiamente partidarios de una ecología profunda, los actores de este tipo de subjetividad se adhieren a una evaluación similar a la que hace Arne Naess (1973) sobre la llamada ecología superficial, cuya critica sólo busca el fin de la contaminación, así como la preservación de los recursos, para el cuidado de la salud y el enriquecimiento de los países desarrollados (p. 95).

Al igual que el ambientalista, el ecologista construye, desde la añoranza de una edad de oro ya pasada, la pertinencia de luchar por un futuro diferente, pero, para pensarlo, puede prescindir del desarrollo económico que provee la industria turística. Para el ecologista, inclusive, el problema de la violencia y la inseguridad proviene de este despilfarro de recursos naturales, y sería incluso mejor un entorno con menos población en la medida que los recursos naturales crecieran. A continuación se muestra ese uso recursivo del pasado para construir una apropiación de los recursos naturales, constitutiva de los sujetos sociales, en palabras de otro activista civil en Acapulco:

(...) yo recuerdo de pequeño, más o menos a la edad que mi hijo andaba ya conmigo en el noventa y pico sacando basura, 10 años, once años, una cosa así, estábamos con mi papá en el malecón con varios lancheros del Acapulco viejo, donde sacaban unos dorados y unos enormes pescados y estaba mi papá con uno de los que tienen yate de pesca, el Chale Bello, que ya falleció, mi papá también ya falleció, y le decía a mi papá y a otro tío 
mío que era Alberto Pintos, que también tenía lanchas de pesca, y aquí utilizamos el "amigo" como "zanca"... "Oye, zanca", viendo, así, hacía, del malecón hacia La Bocana, hacía la entrada de la bahía, dice, “oye, zanca”, ¿cuándo nos acabaremos este mar?... y ya nos los acabamos (Julián, actor civil, comunicación personal)

En el siguiente extracto textual, otro activista civil que forma parte del Colegio de Arquitectos de Acapulco, menciona la crítica al uso de los recursos naturales, sin que ésta constituya necesariamente un discurso antisistémico o un contrapunto al orden económicopolítico. Su clave se articula con la idea de que el problema lo hacemos todos, en la medida que se ha construido una visión de que tanto ciudadanos como gobernantes son apáticos, poco conocedores de la problemática socioambiental y faltos de sentido moral solidario.

(...) no tenemos esa cultura [ambiental], ha sido más importante el lucro, el avorazamiento, y yo diría que hasta hace un poquito la envidia de tener más que otros y que nos lleva a contradecirnos en nuestras acciones. Definitivamente, mientras no tengamos cultura de lo que está sucediendo con el planeta, vamos a seguir teniendo presión para ocupar el territorio en su totalidad y además para, entre comillas, cubrirlo pavimentado y evitar con esto, o provocar más bien con esto, el proceso natural del planeta no se lleve a cabo (Heberto, actor civil, comunicación personal).

El sujeto socioambiental holista conjunta la preocupación por el impacto negativo en el medio ambiente y por la constante presencia de actos violentos hacia la población con crecimiento humano y espiritual. Podríamos comprender esta forma de subjetividad como una búsqueda de incidencia sobre la crisis socioambiental, en la que no sólo se vincula económica y políticamente los problemas medioambientales, sino que también se ubica el origen de la cuestión en un quiebre espiritual entre lo sagrado y lo humano, por lo cual se busca resultados a partir de la concientización desde la religiosidad. Para el sujeto holista, la búsqueda de mejores condiciones socioambientales va de la mano con una educación basada en valores espirituales, y es desde esta narrativa que intenta generar comunidad. Se ha logrado encontrar este tipo de construcción subjetiva en actores como el actual párroco de la comunidad de La Sabana, en la zona baja de la subcuenca del río del mismo nombre; el día 4 de octubre de 2019, éste celebró una misa a la orilla del río, y en este extracto textual explica el objetivo de dicha acción.

(...) estoy buscando construir respuestas, ya no personales sino comunitarias aquí, en este lugar, para ver la forma cómo podemos abordar distintos aspectos que tienen que ver con el deterioro ambiental. De hecho, a partir de la misa que celebré en el río, y la celebré ahí precisamente para sensibilizar..., tres días antes de la misa pues vino esa lluvia fuerte que se llevó todo lo que había de basura y de mugre, bueno nos lo dejó un 
poquito más limpio pero... lo que yo quería era sensibilizar en el lugar y aprovechando la fiesta de San Francisco de Asís que tiene un papel emblemático en todo el tema ecológico buscamos hacer eso...y a partir de ahí ya invité al final de la misa a ver quienes querían anotarse para darle seguimiento al tema; treinta personas se anotaron y ya estamos dándole camino al análisis de la problemática ambiental en esta zona y no sólo lo del río, pero lo del río lo vemos como algo, digamos ,más estratégico, o sea, de más largo plazo, porque no es un tema fácil, y en cambio otros temas más, digamos, inmediatos como el asunto del manejo de la basura, el asunto del aseo de las calles, cosas de ese tipo lo vamos a ir trabajando ya de una manera más inmediata con este equipo. Entonces lo que yo quise con esto es como empezar a hacer un camino en el cual pudiéramos converger distintas personas o actores interesados en el tema (Josué, actor local).

\section{El 'endriago socioambiental'}

Para Sayak Valencia (2010), la necropolítica tiene la capacidad de producir sujetos, aunque las condiciones en las que emerge sean agrestes para la vida. El sujeto de la necropolítica es un homo economicus desechado, sin preparación académica y en condiciones de vida tales, que su única manera de ascender socialmente es incorporándose a una economía de muerte (ser sicario, entrar a la economía informal, vivir en los márgenes de la legalidad). En términos generales, para Valencia (2010), el sujeto de la necropolítica es el endriago; emerge en los espacios gubernamentalmente desatendidos, y su fin último es sobrevivir antes que morir, pero sobrevive mediante la muerte misma. La necropolítica también puede racionalizar la relación vida-muerte, pero el endriago busca defender su propia vida, sin importar que ello suponga la muerte de otros o el uso inmoderado de recursos naturales. Al igual que los sujetos del biopoder socioambiental, construye un sentido moral mediante el cual justifica sus formas de actuar, pero no se basa en la añoranza de un pasado dorado para ello, sino en su propio sentido de supervivencia: es un deber moral proteger a la familia y proveerle recursos, como agua o comida, al margen de si eso supone el exterminio de los otros.

De acuerdo con los actores entrevistados, y cruzando la información con la teoría, es posible caracterizar al endriago socioambiental a partir de cuatro aspectos importante: 1) es alter-comunitario -constituye los vínculos comunitarios a partir de la ilegalidad y prácticas fuera de la ley-; 2) es anti-gubernamental - desconfía profundamente de los actores gubernamentales y encuentra en ellos el origen de la ruptura de relaciones de cooperación regional-, y 3) pone en práctica estrategias de autoprotección ante el abandono estatal en el territorio.

En cuanto al primer punto, es necesario comprender que en el municipio de Acapulco existen territorios histórica y sistemáticamente abandonados por gobiernos 
municipales, estatales y federales. Las zonas altas y medias de la subcuenca del río La Sabana y las comunidades a la orilla de la laguna de Tres Palos son espacios que han tardado en tener acceso no sólo a vías de comunicación, sino también a servicios públicos básicos, como agua y electricidad. Esta tendencia se agudizó con el repunte de la economía turística del puerto, desde los años 40 y 50 del siglo XX, tiempo en el que las políticas de desarrollo urbano del municipio se concentraron en las zonas hoteleras, como Acapulco Dorado, y, desde los años 90, en la Zona Diamante. La desigualdad en la atención gubernamental se expresó de manera dramática a nivel geográfico: desarrollos habitacionales, tiempos compartidos y hoteles de playa en la zona costera, y alta marginación en las zonas altas del municipio (Rodríguez, 2017, p. 27). Así, el sentido de las relaciones comunitarias no pudo desarrollarse en los términos idílicos que propone García Linera (1997), en que la producción económica se sustentara en el valor de uso común para generar mayor cooperación entre los actores.

En zonas de abandono estatal, como las regiones altas y medias de Acapulco, la comunidad se crea a partir de la resolución conjunta de problemas como el desabasto de agua o la elaboración de estrategias de seguridad pública por fuera de la ley del Estado. Emerge, entonces, una red de relaciones entre lo legal y lo ilegal, tejida en lo que Das y Poole (2008) denominan los márgenes del Estado, es decir, "espacios de permisividad", donde el ejercicio de la legalidad estatal - entiéndase estado de derecho- resulta limitado y ocasionalmente se recurre a otros criterios para controlar o pacificar los conflictos (p. 24). El párroco de la comunidad La Sabana, que seis meses antes de ser entrevistado fue también párroco de Kilómetro 30, habla de la existencia del régimen de cooperación entre lo legal e ilegal, y cómo a partir de éste puede generarse comunidad.

En el 30, es la CAPAMA la que administra el agua y a la que hay que pagar los recibos, pero en realidad no hay agua a lo largo de dos o tres meses... Entonces es el negocio de particulares, negocio de particulares que tienen... buscan acceso a fuentes de agua para venderla (Josué, actor local, comunicación personal).

Otro de los entrevistados, Crisanto, profundiza un poco más sobre la venta de agua por parte de particulares; en su relato, es interesante notar que dicha actividad se presenta a la par de los sistemas de distribución de agua para uso doméstico de la paraestatal CAPAMA, con lo cual emerge un vínculo cooperativo entre la esfera de lo institucional y lo extralegal para la satisfacción de la necesidad de acceder al agua:

Mire, aquí todo se maneja... se maneja por medio de la CAPAMA... pero llega el momento donde la CAPAMA ya no le alcanza en surtirles todos el poblado del treinta por 
medio de tubería de agua (...) ya cuando ven las personas que ya no les alcanza el agua entran los que andan vendiendo con su rotoplas... surtiéndole a la gente que ya no les alcanza el agua... que ya está más alta donde ya no sube el agua (...) y ahí es donde entran los que andan vendiendo el agua pues con tinacos..., aja..., para que les alcance a surtir a todo el pueblo (Crisanto, actor local, comunicación personal).

La búsqueda de nuevas fuentes de agua no necesariamente supone, desde esta lógica comunitaria, el registro de la concesión del agua. Los consejos comunitarios de agua se constituyen fuera de la intervención de la Comisión Nacional (CONAGUA), y es en estas instancias no registradas a nivel gubernamental donde se toman acuerdos y se solucionan conflictos. Una profesora de la preparatoria de Kilómetro 30 refiere cómo operan estas instancias, en el marco de la deliberación de acuerdos y conflictos:

Los conflictos se han arreglado a través de ahorita que propusieron otro nuevo comité; cada año se va cambiando, no se deja a la misma persona; se pone igual un presidente, el secretario y el tesorero. Ahorita el conflicto es de que hicieron mal uso de los tanques, solamente abastecían a las familias del comité; a las familias que estábamos más abajo no nos llegaba el agua. Entonces un señor, que es muy de años aquí, don Melquiades, él se encargó de ir, con su sobrino Francisco, a ver las tomas de agua al pozo; él decidió con su sobrino subir y arreglar por ellos mismos las mangueras, porque a las mangueras se le mete aire, y cuando se les mete el aire, pues obviamente el agua no baja, se retiene. Entonces ellos tomaron de ir todo el camino hasta el tanque arreglando las mangueras. También (los miembros del comité anterior) hicieron mal uso del campo, porque donde está el tanque de agua, hay un lugar, un área verde pues muy bonita, porque hay árboles para que le den sombra al pozo y no se seque; esa es la idea de que el agua siga brotando por los árboles que están ahí. Entonces, el comité pasado lo que hizo fue cortarlos, cortar algunas partes y echar líquido para que murieran las plantitas que estaban alrededor; ahorita lo que volvieron a hacer (los del nuevo comité) es llevar árboles frutales para sembrarlos en esa área y volver a haber un poquito más de agua. Los problemas siempre se resuelven en asambleas, se junta toda la colonia; ésta, la colonia Guadalupe, y a veces, cuando hay muchos problemas más fuertes, se manda traer a la otra colonia de más arriba, que se llama La Unión, para decidir cómo se va a solucionar, porque aquí todos pues tenemos voz y voto sobre el agua (María, actor gubernamental, comunicación personal).

Detrás de esta búsqueda de construcción de comunidad fuera de la lógica gubernamental, se encuentra un profundo rechazo a la intervención estatal en los asuntos de estos espacios, lo que ha dado pie no sólo a la constitución de los consejos comunitarios de agua no reglamentados por la CONAGUA, sino también a la autodefensa comunitaria, con expulsión de fuerzas de seguridad pública nacional (policías municipales y estatales, ejército 
y marina). Esto se da en un contexto de violencia e inseguridad, que hace de Acapulco una de las ciudades con mayor número de homicidios por cada 100000 habitantes a escala mundial (Seguridad, Justicia y Paz, 2019). ${ }^{5}$ El comisario de Kilómetro 30 menciona, de manera tajante, el rechazo en su comunidad a la presencia de policías y militares, y los mecanismos usados para expulsarlos.

Pues aquí no hay de ese tipo... de así no... seguridad tenemos... aunque sea de aquí mismo del pueblo; el gobierno casi no entra para acá, aquí es una sola pieza pues... que nomás no, no dejamos entrar a nadie... porque nos ponemos, hasta el gobierno se quiere meter a veces para acá y nos ponemos enfrente y nomás no dejamos entrar a nadie. El apoyo del gobierno no, porque un tiempo sí vinieron los federales y andaban nomás agarrando al que... y sí pues ahí fue donde se puso la gente y le dijimos que no queríamos gobierno aquí porque ellos mismos venían a hacer sus males aquí... sí, cerramos la carretera, se vio hace como hace unos 8, 10 años; se cerraron las carreteras para no dejar pasar a ningún gobierno... se andaban metiendo a las casas el gobierno; no, que "este es mañoso" y "este es asaltante", decían los federales; el chiste es que a todos se los querían llevar, a los chavos que encontraban, o sea, haga de cuenta que eran delincuentes pues, y la verdad no ... y sí, muchos se quejaron, se llevaron como a seis chavos, se metieron a sus casas y eran sin problemas (inocentes) los muchachos... y se unió la gente y le caímos a la federal y nos los entregaron; y desde entonces dijimos que ya no. Antes aquí estaba más feo que en Xaltianguis, ahorita Xaltianguis está feísimo... también aquí un tiempo se puso feo, pero hasta que nos pusimos, nos armamos de valor y hablamos con el gobierno que no... y sí, desde entonces dejaron de venir, todo tranquilo. Aquí, temor de algún asalto, de un secuestrador, nada, para nada; nos cuidamos entre nosotros mismos... [Sobre la sanción de delitos en la localidad] Pues aquí mismo, el que cometa el delito es el que paga; tiene que pagar lo que hizo, el daño que haga aquí en esta comunidad (Darío, actor local, comunicación personal).

Otros testimonios dan cuenta de que esta expulsión de las fuerzas policiales y militares de localidades como Kilómetro 30 no fueron actos desprovistos de intereses fuera de la ley. Ante la pregunta sobre si efectivamente había ocurrido la expulsión de fuerzas de seguridad, un expárroco de Kilómetro 30 respondió: "sí [ha pasado], pero ha sido por inducción de los grupos de la delincuencia; o sea, no han sido solos (Josué, actor local,

\footnotetext{
${ }^{5}$ En Acapulco, no sólo los actores locales padecen los eventos de violencia e inseguridad, también lo hacen los trabajadores gubernamentales y concesionarios privados de servicios públicos. Martín, trabajador de limpia pública, menciona las experiencias que han tenido que pasar en este contexto: "nosotros nos hemos enfrentado a todas esas situaciones... definitivamente no paramos, o sea, no por eso ya no dejamos de ir... a nosotros, a nuestros choferes los han cacheado, les han dado sus golpes, hasta ahí no ha pasado a mayores... han llegado... "muévete hijo de la chingada..." Los vienen persiguiendo, se vienen persiguiendo... los choferes ya tienen códigos, ya saben que en esos lugares deben de andar más rápido, muy vivos, que si viene alguien, quítate, el chofer debe de dejar inclusive hasta a los ayudantes, como sea... debe de abrirles el paso (Martín, actor gubernamental, comunicación personal).
} 
comunicación personal). Los pobladores y actores socioambientales de la región subcuenca del río La Sabana y laguna de Tres Palos han constituido, para su sobrevivencia y protección, una red de relaciones entre lo legal y lo ilegal, producto de un estado de excepción en el que la ausencia de intervención estatal dio pie a órdenes de legalidad paralelos: Javier Auyero (2007) denomina zona gris a esta indistinción (p. 53). No diferenciar entre lo legal y lo ilegal, los ciudadanos y los inciviles, puede resultar problemático no sólo para constituir un estado de derecho, pero bastante práctico para mantener el control mediante el gobierno privado indirecto (Mbembé, 2006), sino también para la emergencia de lo que Antonio Fuentes (2019) llama “órdenes comunitarios de regulación de seguridad”, es decir, estrategias de reacción de los actores comunitarios ante los embates de grupos criminales claramente definibles o de actores estatales que operan en conjunto con criminales, con las cuales se garantiza la sobrevivencia en entornos necropolíticos (p. 171).

\section{CONCLUSIONES}

Las conclusiones a las que hemos llegado durante el estudio nos permiten comprender el proceso de constitución de subjetividades en contextos de violencia y securitización socioambiental. Uno de los primeros elementos que debemos considerar, como apunte conclusivo, es la complejidad del vínculo socioambiental que los actores de la subcuenca expresan mediante discursos y acciones. En otras palabras, sostenemos que no existe una sola vía de relación entre humanos y naturaleza en el mencionado espacio ecosistémico, sino que existen múltiples caras de la subjetividad socioambiental en torno a la subcuenca. Sólo podemos entender la emergencia de dichos discursos y acciones, a través de la evolución histórica de una ciudad que no nació siendo destino turístico, sino que se construyó como tal, desde los años 30 del siglo pasado, a partir de políticas federales y estatales que han derivado en la puesta en marcha de una economía más centrada en el ocio y la permisividad para con el turista, ${ }^{6}$ que en una economía con justicia social y ambiental. En ese sentido, vemos actores preocupados por el desarrollo de un vínculo más racional entre seres humanos y naturaleza; otros, orientados a la acumulación de ganancias económicas; otros,

${ }^{6}$ No fue gratuita la pifia, posteriormente corregida, de la publicidad del Fideicomiso de Promoción Turística de Acapulco, denominada Mom, I'm in Acapulco! (Espinosa, 2020), en la que pueden escucharse afirmaciones como las siguientes: "Desde 1930, Acapulco ha hecho sus propias reglas; impulsados por los más grandes de cada época (...) hoy dejamos de ser una postal del pasado, hoy cambiamos las reglas. De hecho, ¡no hay reglas $;$ Come lo que quieras, diviértete de día, de noche o de madrugada (...) aquí puedes ser quien tú quieras". Acapulco, como destino turístico, se ha construido sobre la base discursiva de que es un lugar donde el turista puede vivir sin límites, cosa negada para el acapulqueño nativo, quien vive del (o a costa del) turista. Este ethos explica tanto la concesión ilimitada de terrenos en la franja costera a la industria hotelera y la construcción de lujosas mansiones que afectaron ecosistemas marinos, como el caso de la vivienda de Maximino Ávila Camacho en la playa de Caleta (Ramírez Sáiz, 1987, pp. 485-486) y la presencia de redes de tráfico de drogas al menudeo y trata de infantes para su prostitución (Illades \& Santiago, 2019), entre otros aspectos. 
más preocupados por la sobrevivencia, a pesar de la desigualdad y la persistente violación a los derechos humanos. Estas subjetividades son, en suma, la respuesta social a un proceso de degradación socioambiental, luego de la manufactura política y económica de riesgos (Giddens, 1998).

El grueso de los estudios que informan del proceso de generación de sentido en torno a los conflictos socioambientales en la subcuenca río La Sabana-laguna de Tres Palos se ha dado en clave de conceptos como percepciones o representaciones. La limitación teóricometodológica que dichos estudios han evidenciado pasa por los alcances que, en términos más amplios, tienen estos conceptos. Para autores como Moscovici (1979) y Jodelet (1986), las representaciones son 1) constituidas colectivamente; en éstas, 2) los individuos muestran con su visión del mundo un pensamiento generalizado más que una relación entre discurso y acción; y 3) si bien puede haber cierta profundización en el proceso de construcción de las representaciones, su importancia radica en la magnitud de su presencia en la conciencia colectiva. Es evidente que la constitución de sujetos en contextos de dominación socioambiental significa un acercamiento para complejizar el análisis de la realidad regional, y ello nos aporta aún más preguntas que respuestas.

En el contexto actual, la constitución de la subjetividad no necesariamente pasa por un régimen de legalidad biopolítica, pero envuelve intrincadas tramas de relaciones con grupos fuera de la ley para incidir sobre problemas de carácter socioambiental. La historia de las relaciones políticas y económicas en Guerrero se ha caracterizado por la emergencia de órdenes paralegales en territorios de difícil acceso para actores de los tres niveles de gobierno (Illades, 2000), y el análisis que hemos expuesto confirma esta tendencia histórica, de acuerdo con la problemática de la gestión de los recursos naturales a nivel subcuenca, pero con base en la comprensión de que dicha gestión no está desvinculada de otros riesgos sociales, como la desigualdad y la violencia criminal. Finalmente, sostenemos que el orden económico extractivista no se diferencia claramente de un régimen caracterizado por el uso discrecional de la violencia y el mantenimiento de las desigualdades (Mbembé, 2006). 
Figura 4. Tabla de entrevistados y posiciones en el Mapeo de Actores

\begin{tabular}{|c|c|c|}
\hline Nombre del actor (pseudónimo) & Tipo de actor según mapeo & Procedencia (instancia, organización) \\
\hline Armando & Gubernamental & Funcionario H. Ayuntamiento \\
\hline Ernesto & Gubernamental & Exdirector de CAPAMA \\
\hline Gerardo & Gubernamental & Trabajador CAPAMA \\
\hline Vitelio & Gubernamental & Trabajador CAPAMA \\
\hline Soledad & Gubernamental & Directora de preparatoria \\
\hline María & Gubernamental & Profesora de preparatoria \\
\hline Martín & Gubernamental & Concesionario de Recolección de Basura \\
\hline Roberto & Gubernamental & Saneamiento Básico \\
\hline Rodrigo & Gubernamental & Saneamiento Básico \\
\hline Jehú & Gubernamental & Saneamiento Básico \\
\hline Hilario & Civil & Consejo de Cuenca \\
\hline Natanael & Civil & Consejo de Cuenca \\
\hline Yireh & Civil & Organización de Educación Ambiental \\
\hline Julián & Civil & Organización Ambientalista \\
\hline Julio & Civil & Organización Ambientalista \\
\hline Luis & Civil & Oceanólogo y activista \\
\hline Heberto & Civil & Arquitecto y activista \\
\hline Jonás & Civil & Biólogo y activista \\
\hline Rodrigo & Civil & Arquitecto y académico \\
\hline Crisanto & Local & Comisario Ejidal \\
\hline Amelia & Local & Vecina de comunidad rural \\
\hline Marcos & Local & Habitante en zona rural \\
\hline Darío & Local & Comisario Ejidal \\
\hline Pablo & Local & Habitante en zona rural \\
\hline Josué & Local & Sacerdote local \\
\hline
\end{tabular}

Fuente: Elaboración propia.

\section{REFERENCIAS}

AlfiE, M. (2001). Nuevos sujetos sociales: el movimiento ambientalista. El cotidiano, 106, pp. 66-76.

AuYERO, J. (2007). La zona gris. Violencia colectiva y política partidaria en la Argentina contemporánea. Buenos Aires: Siglo XXI.

BARTRA, A. (1997). Guerrero Bronco. Campesinos, ciudadanos y guerrilleros en la Costa Grande. México: Ediciones Sinfiltro.

DAs, V. \& PoOle, D. (2008). El Estado y sus márgenes. Cuadernos de Antropología Social. 27, pp. 19-52.

DE la Garza, E. (2000). Subjetividad, cultura y estructura. México: UAM-I, ClACso (Documento de trabajo). 
De la llata, M., JuÁrez, A. \& SAmpedro, M. (2018). Environmental perceptions to define a tipology of environmental delinquency in the management of MSW. RUII. Revista UPIICSA Investigación Interdisciplinaria, 4(1), pp. 1-14.

Del Carmen, V., Sampedro, L., Rodríguez, A., Juárez, A., Reyes, M. \& Silva, S. (2018). Municipal Solid Waste Management Course: A Case Study in Xaltianguis, Guerrero, México. International Journal of Applied Environmental Sciences, 13(19), pp. 787-800.

Del Cairo, C., Montenegro-Perini, I. \& VÉleZ, J. (2014). Naturalezas, subjetividades y políticas ambientales en el Noroccidente amazónico: reflexiones metodológicas para el análisis de conflictos socioambientales. Boletín de Antropología, 29(48), pp. 13-40.

Esteva, G. (1997). Desarrollo. En Sachs, W., Diccionario del Desarrollo: una Guía del Conocimiento como Poder (pp. 53-78). Cochabamba, Bolivia: PRATEC-CAI.

EsTÉVEZ, A. (2019). Mediación en la necropolítica y la biopolítica: produciendo el homo economicus neoliberal y desechable. En EsTÉVEZ, A. (coord.), Mediación en el régimen de subjetividad bio/necropolítica: de la minería de datos al consumo comercial de lo violento. México: UNAM.

ESPINOsA, K. [@Korno] (2020, agosto 5): Oye, @SECTUR_mx, se te borró esto [video]. Twitter. Recuperado de https: //bit.ly/3rgVWNv.

FouCAult, M. (2018). Seguridad, territorio, población. México: FCE.

Foucault, M. (2007). El Nacimiento de la biopolítica. México: FCE.

FUENTES, A. (2019). El Estado son ustedes. Zona gris y defensa comunitaria en Michoacán. En Fuentes, A. \& FInI, D., Defender al pueblo. Autodefensas y policías comunitarias en México. Puebla: BUAP.

Galán, E., Rodríguez, A. \& Rosas, J. (2020). Gobernanza hídrica como securitización socioambiental en la subcuenca La Sabana-Tres Palos, Acapulco. Regions and Cohesion. 11(1).

García Linera, A. (1997). Forma valor, forma comunidad. Aproximación teórica-abstracta a los fundamentos civilizatorios que preceden al Ayllú Universal. La Paz, Bolivia: Comuna, Muela del Diablo Editores, CLACSO.

GidDENS, A. (1998): Sociedad de riesgo: el contexto de la política británica. Estudios demográficos y urbanos, 39, pp. 517-528.

GonzÁlez, J., Quiterio, A., Niño, N., Reyes, M. \& TORres, G. (2012). Evaluación ambiental territorial de la cuenca Río La Sabana-Laguna de Tres Palos. En SAmpedro, M. \& GonZÁleZ, J., Calidad Ambiental y Desarrollo Sustentable. Indicadores. Chilpancingo: Universidad Autónoma de Guerrero (UAGro).

ILlADES, C. (2000). Breve historia de Guerrero. México: FCE/ COLMEX. 
Illades, C. \& Santiago, T. (2019): Mundos de muerte. Despojo, crimen y violencia en Guerrero. México: UAM, Gedisa.

JODELET, D. (1986). La representación social: fenómenos, concepto y teoría. En Moscovici, S. (comp.), Psicología social II. Madrid: Paidós.

Kvale, S. (2011). La entrevista en la investigación cualitativa. Madrid: Morata.

LaZZArato, M. (2013). La fábrica del hombre endeudado. Buenos Aires: Amorrortu.

LEFF, E. (2000). Tiempo de sustentabilidad. Revista de Ciencias Ambientales, 18(1), pp. 60-65.

López, V., ToAche, G., López, J., García, S., Benítez, J., JuÁrez, A. \& Rivas, M. (2013). Percepción de la comunidad de Barra Vieja sobre la contaminación de la Laguna de Tres Palos, en Guerrero. Ciencia en la Frontera: Revista de Ciencia y Tecnología de la UACJ. 21(2), pp. 79-102.

MBEmBÉ, A. (2006). Necropolítica. Madrid: Melusina.

Moscovici, S. (1979). El psicoanálisis, su imagen y su público. Buenos Aires: Huemul.

Murillo, D. (2004). Falacias del Desarrollo Sustentable. Una crítica desde la metamorfosis conceptual. Economía, Sociedad y Territorio 4(16), pp. 635-656.

NAESS, A. (1973). The shallow and the Deep. Long-range ecology movements: A summary. Inquiry, 16, pp. 95-100.

Navarro, M. (2010). Horizontes de sentido de las luchas socioambientales en México: redención, memoria, lucha contra el progreso, presente revolucionario $\mathrm{y}$ anticapitalismo. Recuperado de https: / / bit.ly/3bMlVpt.

NAVArRo, M. (2013, mayo). Las luchas indígenas y campesinas contra el despojo capitalista en México: subjetividades políticas en la defensa y gestión de los bienes comunes naturales. Boletín Onteaiken, 15, pp. 71-84.

Navarro, M. \& PinedA, E. (2009). Luchas socioambientales en América Latina y México: nuevas subjetividades y radicalidades en movimiento. Revista Bajo el Volcán, 14.

POPPER, K. (1962). La lógica de la investigación científica. Madrid: Tecnos.

RAmírez SÁIz, J. (1987). Turismo y medio ambiente. El caso de Acapulco. Estudios Demográficos y Urbanos, 2(3), pp.479-512.

Rosas, J. \& CORTÉS, A. (2018). Turismo y Medio Ambiente. En SÁnChEZ Infante, A. \& Rosas ACEVEDO, A. (coords.), Medio ambiente, sociedad y turismo (pp. 51-82). México: Porrúa.

RoDríguEZ, A. (2017). Acapulco: ciudad turística y globalización. Reflexiones en la búsqueda de nuevas líneas de investigación. En RODRÍGUEZ, A., ROSAS, J., Quintero, D. \& RuZ, M. (coords.), Los retos del desarrollo en Acapulco. México: UAGro. 
SÁNCHEZ INFANTE, A. (2018). Aspectos para lograr la sustentabilidad en la zona norte de la Laguna de Tres Palos. En SÁnchez Infante, A. \& Rosas Acevedo, A. (coords.), Medio ambiente, sociedad y turismo (pp. 7-26). México: Porrúa.

SÁnChez Infante, A. \& Rosas ACEvedo, A. (coords.) (2018). Medio ambiente, sociedad y turismo. México: Porrúa.

SAldaña, E. \& PÉREZ, S. (2015). Torrente y su mal manejo. Acapulco: UACA-UAGro.

SEGURIDAD, Justicia y PAZ (2019). Las 50 ciudades más violentas del mundo 2018. Estudio del Consejo Ciudadano Para la Seguridad Ciudadana y la Justicia Penal A. C. Recuperado de: https: / / bit.ly/3sr79uW.

Tischler, S. \& NAVArro, M. (2011). Tiempo y memoria en las luchas socioambientales en México. Desacatos, 37, pp. 67-80.

Trentini, F. \& SOrRoche, S. (2016). Repensando los conflictos socioambientales desde una ecogubernamentalidad en fricción. Estudios Políticos, 49, pp. 132-147.

TrianA, J. (2017). Percepción de inseguridad en polígonos geográficos prioritarios en Acapulco. Espiral. 24(70), pp. 221-249.

VAlenCIA, S. (2010). Capitalismo Gore. Madrid: Melusina. 